\title{
Five years of heartsink patients in general practice
}

\author{
T C O’Dowd
}

\begin{abstract}
"Heartsink" patients exasperate, defeat, and overwhelm their doctors by their behaviour. A group of such patients was followed up over five years in a general practice, and this paper describes what happened to them. As a group they were often in employment and in stable relationships, though women were over represented. Half the group were subjected to a management plan which seemed to make them less heartsink over the five year period. While heartsink patients often have serious medical problems, they are a disparate group of individuals whose only common thread seems to be the distress they cause their doctor and the practice. Heartsink as a phenomenon has features that are unique to general practice.
\end{abstract}

\section{Introduction}

There are patients in every practice who give the doctor and staff a feeling of "heartsink" every time they consult. They evoke an overwhelming mixture of exasperation, defeat, and sometimes plain dislike that causes the heart to sink when they consult. Ellis, a general practitioner, coined the phrase "dysphoria" to define "the feelings felt in the pit of your stomach when their names are seen on the morning's appointment list." Groves, a psychiatrist, used the term "hateful patient" and defined four stereotypes: dependent clingers, entitled demanders, manipulative help rejectors, and self destructive deniers.

Much of the research so far has concentrated on frequent attenders rather than on heartsink patients. Follow up in many of these studies has been short, and all investigators highlight the need for a long term study to describe outcome in this difficult group of patients. There is of course overlap, but concentrating on frequent attenders does not highlight that group whom the doctor finds most difficult. This implies an element of self disclosure not normally forthcoming in medical practice.

This paper describes $(i)$ a group of patients considered by a practice to cause heartsink, (ii) an intervention in management, and (iii) outcome after five years, and (iv) discusses a common but neglected problem.

\section{Background}

The definition-There are problems of definition of heartsink because all doctors' hearts do not sink for the same reasons, yet Ellis's definition has an intuitive ring about it. I have used the term "heartsink" for two main reasons: it was in use in the practice when I joined, and those who hear it for the first time gain a rapid understanding of the problem. While it lacks the charm of many neologisms, it is none the less descriptive. Ellis's term "dysphoria" is more elegant but sanitises a messy feeling and focuses attention away from the sufferer onto the patient. "Heartsink" more clearly refers to the doctor's emotions which are triggered by certain patients.

The practice-In 1980 I joined the NHS practice of the University of Wales College of Medicine as a vocationally trained principal in general practice. The practice, which does not use a deputising service, has about 8000 patients and is divided into three "mini" practices each of which is run by two principals on a half time basis with a trainee assistant. The practice population mainly consists of social classes III to $\mathrm{V}$ according to the Registrar General's classification. The average consultation rate between doctor and patient a year is $3 \cdot 7$, excluding antenatal care, child health and family planning clinics, and telephone contacts.

The problem-It became apparent to me in my first year in the practice that there was a group of patients who were causing stress to the practice. These patients seemed to be dissatisfied with the services provided, placed many demands on the practice, and were often frequent attenders with seemingly endless complaints. This group of patients caused a feeling of "heartsink" in staff in the practice which was often borne with resignation but occasionally led to pejorative remarks being made. With the help of my partner and the receptionist I compiled a list of such patients or families. I reviewed their case notes and summarised each family's reasons for consulting and outlined their present management.

The patients - Twenty eight individuals were considered to be heartsink by the practice, 22 women and six men ranging in age from 18 to 68 years. Twenty two were married or cohabiting and six were single, separated, divorced, or widowed. Two lived alone and the remainder shared their address with a partner or children. Nineteen were employed or had an employed person in the home; two were retired. One family was on the at risk register. In five cases the heartsink patient actually had a lower consultation rate than another member of their family. As a group they are demographically similar to the rest of the practice.

\section{Intervention}

Over the next six months at a series of lunchtime meetings a heartsink patient or family from the list was selected for discussion in depth because they were ranked as being the most heartsink on the list. The discussion group consisted of three general practitioners, a health visitor, a general practitioner trainee, and occasionally a psychologist. The function of each meeting was to share information, define apparent problems, formulate a plan of management, and provide support for the professional who was to deal most with a particular patient. The management plan was then entered in each patient's notes. In addition, at each meeting follow up information was presented on cases already discussed. The meetings stopped after six months because of pressure of time and doubt that the 
effort was worth while. Inadvertently this has provided two comparison groups: one group who had a management plan and one whose care was unplanned and reactive.

\section{Review and outcome}

Nine of the group had serious medical conditions in 1980. These are listed in table I together with their state on review in 1984. The remaining group of 19 presented with multiple vague complaints. In the five year period three new serious medical problems emerged, in the last group: one patient developed carcinoma of the transverse colon, one Addison's disease, and one hypertensive patient had a minor stroke. The woman who developed cancer of the colon rarely visited after her operation and remains well; the other two patients continue to consult frequently and are well. Thus 12 of 28 either had or developed serious medical problems.

Nine of the 28 were selected for discussion because it was thought they caused the most heartsink in the practice. These were not all the same nine patients as in table I. A management plan was formulated as a result of the discussion meeting. The commonest theme in the management plan was that the heartsink patient should see the same doctor, a principal, every time for future consultations, but the plans were tailored to take account of each patient's circumstances.

While a decline in the consultation rates was not the aim of our meetings, the mean consultation rates for both groups fell. The rates for the heartsink patients in the group not discussed fell from 16 to 11 a year, while those for the rest of their family stayed at about three a year (range $2 \cdot 5-3 \cdot 3$ ). The mean consultation rates for the heartsink patients and their families in the discussion group fell appreciably from 19 to seven and that for the family also fell from six to two consultations a year. There were clearly differences between the two groups at the outset, and it is likely that we discussed the more demanding of the two groups first. It is also likely that their consulting behaviour may have been altered by intervention-the so called Hawthorne effect.

TABLE I-Known serious medical problems among nine patients who consulted of ten in general practice

\begin{tabular}{llll}
\hline Patient & Medical problem & State in 1980 & State in 1984 \\
\hline 1 & Thyroiditis & Quiescent & Quiescent \\
2 & Hypercholesterolaemia & Disregarding it & Moved out of practice area \\
3 & Hypertension & Controlled with drug treatment & Had a minor stroke \\
4 & Asthma & Occasional flare up & Stable \\
5 & Depression & Active & Mood normal \\
6 & Panic attacks & Getting worse & Left practice \\
7 & Sarcoidosis & No problems & No problems \\
8 & Rheumatoid arthritis & Controlled with drug treatment & Well controlled \\
9 & Stroke and chronic airways disease & Regular house visits; flare up of chest & Stable \\
\hline
\end{tabular}

The total group was mainly managed in the practice. Four attended outpatients departments-one recently and one occasionally attends a pacemaker clinic. This is unusual as many such patients do the rounds of various outpatients departments and it may be the reason that the practice has so many heartsink patients. As a group most have been registered with the practice for five years and only one had been registered for a year. The group not discussed saw various doctors in the practice-often a succession of trainees-and often broke appointments by not turning up.

Putting the management plan into action-Table II summarises the problem definition, management, and outcome in nine patients who were discussed. The problem definition was of a strong medical nature, while the management was largely doctor centred despite a health visitor and psychologist participating in the management meetings. There was one confrontation which was therapeutic and revealed that the wife, a low consulter, encouraged the rest of the family to consult frequently. Two "truces" developed between doctor and patient, with a decline in consultation rate and containment being achieved.

Those who left-Over the five year period eight of the 28 patients left the practice; four from the group who were discussed and four from the other group. This is less than for the rest of the practice, which has a yearly patient turnover of $10 \%$. Two patients left shortly after the management plan was put into action: one who had recurrent chest pains with unresolved grief moved in with her new partner out of the practice area; one patient with personality problems also left but for unknown reasons. Two patients, one from each group, made known their dissatisfaction about the practice and left during the five years. The lowest consulter (less than five consultations a year for herself) caused persistent anxiety because of denial of her cardiovascular risk factors. This caused us alarm but not her. She most often consulted on her husband's behalf requesting chest medicines for him but declined requests to have him seen. She moved out of the area for unknown reasons. Two patients with marital problems, one including domestic violence, also left for unknown reasons after two years with the practice.

Five years on-Five years after compiling the original heartsink list I compiled another list of heartsink patients with the same partner and same receptionist. This time there were 19 instead of 28 heartsink patients, and the list contained seven from the original list: six of the seven were from the group not discussed and one was from the discussion group. If, as I suspect, we discussed the worst cases this is a genuine improvement. There may have been fewer heartsink patients five years later because of greater experience and an interest in the problem.

TABLE II-Problems defined, management, and outcome of patients who were discussed by the practice

\begin{tabular}{|c|c|c|c|c|c|}
\hline \multicolumn{3}{|c|}{$\begin{array}{l}\text { Patient } \\
\text { Age (years) } \\
\text { sex }\end{array}$} & \multirow{2}{*}{$\frac{\text { Problems defined in } 1980}{\text { Panic attacks palpitations }}$} & \multirow{2}{*}{$\begin{array}{l}\text { Management } \\
\text { Contract drawn up; see same doctor }\end{array}$} & \multirow{2}{*}{$\begin{array}{l}\text { Outcome } \\
\begin{array}{l}\text { Consultations declined; saw same doctor for three years; left } \\
\text { practice after divorce }\end{array}\end{array}$} \\
\hline 1 & 36 & $M$ & & & \\
\hline 2 & 41 & $M$ & Multiple minor illness (whole family) & Husband and wife interviewed confronted & $\begin{array}{l}\text { Husband got a job; consultations declined to a high plateau with } \\
\text { same doctor }\end{array}$ \\
\hline 3 & 44 & M & Sarcoidosis; chest pains & $\begin{array}{l}\text { Permit sick certification as he needs; watch pain killers; } \\
\text { support wife }\end{array}$ & $\begin{array}{l}\text { Still working; regular sick certification; occasional antidepressants; } \\
\text { same doctor }\end{array}$ \\
\hline 4 & 34 & $\mathrm{~F}$ & Heavy periods; obese; pacemaker in situ: why? & $\begin{array}{l}\text { To sort out pacemaker; referral to gynaecologist; diet } \\
\text { advice }\end{array}$ & $\begin{array}{l}\text { Consultation declined; still has menorrhagia and obesity; uses } \\
\text { pacemaker to get her own way; sees both partners }\end{array}$ \\
\hline 5 & 53 & $\mathrm{~F}$ & $\begin{array}{l}\text { Hypercholesterolaemia, obese; always came about } \\
\text { husband's chestiness }\end{array}$ & Take off clofibrate; dietary advice & Moved out of area after two years \\
\hline 6 & 39 & $\mathrm{~F}$ & $\begin{array}{l}\text { Frequent skin and urinary symptoms; attending many } \\
\text { outpatients departments social services }\end{array}$ & $\begin{array}{l}\text { Reduce number of agencies consulted; family } \\
\text { relationships to be explored }\end{array}$ & $\begin{array}{l}\text { Consultations declined; developed cancer in transverse colon 1983; } \\
\text { seldom consulted after } 1983\end{array}$ \\
\hline 7 & 47 & $\mathrm{~F}$ & $\begin{array}{l}\text { Headaches, requests for analgesics; marital problems; } \\
\text { personality problems }\end{array}$ & See same doctor; watch drug use & Left practice within one year \\
\hline 8 & 36 & $\mathrm{~F}$ & $\begin{array}{l}\text { Children on at risk register; mother remarried after } \\
\text { death of husband }\end{array}$ & Health visitor support; developmental assessments & $\begin{array}{l}\text { Children went into care; mother rehabilitated; "earned" children's } \\
\text { return; occasional school problems; same doctor }\end{array}$ \\
\hline 9 & 26 & $\mathrm{~F}$ & Chest pains, unresolved grief & Explore grief & $\begin{array}{l}\text { Backed off; moved in with new partner; left practice within one } \\
\text { year }\end{array}$ \\
\hline
\end{tabular}




\section{Discussion}

Heartsink patients are a great source of stress to doctors, and the feeling of heartsink may be the only common thread joining a disparate group of difficult patients. Because the problem has never been quantified in practices there is often a feeling that it is bigger than it really is. In this study getting more information about the patient and family seemed to make them less heartsink. With a greater understanding of the patient, it is likely that the doctor was relieved of any clinical insecurity and became more positive about the patient. These patients grated with the practice; however, it is likely that the doctors' negative feelings were transmitted to the staff or to each other as in Stockwell's study of nurses and unpopular patients. ${ }^{6}$

The meetings were structured to search for reasons for the patients' discontent, which now sounds like missing the point. None the less searching for such reasons often produced dilemmas which meant the discussion group had achieved a degree of sharing and support that might not have happened if it had been the declared purpose of the group. The group always formulated a management plan. This again might seem inappropriate, but it changed an often helpless doctorpatient relationship into a more positive state of affairs. Undoubtedly, the negative feelings such patients aroused in us made us feel "unprofessional," causing puzzlement, frustration, and disappointment. Our scientific and medical training, hurried working conditions, and unsupported professional needs concentrates our preference for standardised behaviour.

Heartsink patients cause much clinical insecurity. It is reassuring to know that the heartsink patients in this group do not seem to have suffered from missed diagnoses, but like the results of other studies have shown many had chronic medical and psychological problems. $^{3578}$ There is of course the great danger that such illness may be poorly managed when the doctor would really prefer not to see the patient.

The nature of this work can be likened to what Marinker has called a journey into the interior of general practice. ${ }^{9}$ It is a lonely journey that many doctors make regularly and is one of the most complex problems we face. The features are unique to general practice. In the past general practice has permitted and benefited from outside views of its problems; we need help with this problem because we are part of it and thus find understanding it difficult.

Many clinicians and non-clinicians have helped in the writing of this paper. Particular thanks go to my colleagues at Llanedeyrn Health Centre, Cardiff and my colleagues in the Department of General Practice, Nottingham. Professor John Horder provided valuable critical comment.

1 Ellis CG. Making dysphoria a happy experience. BrMed $\mathcal{~ 1 9 8 6 ; 2 9 8 : 3 1 7 - 8 . ~}$ 2 Groves JE. Taking care of the hateful patient. $N$ Engl f Med 1978;298:883-7. 3 Westhead JN. Frequent attenders in general practice: medical, psychological and social characteristics. $\mathcal{J} R$ Coll Gen Pract 1985;35:337-40.

4 Ries RK, Bokan JA, Katon WJ, Kleinman A. The medical care abuser: differential diagnosis and management. F Fam Pract 1981;13:257-65.

5 Courtenay MJF, Carwen MP, Dave D, Robinson J, Stern MJ. Frequent attendance in a family practice. $\mathcal{F} R$ Coll Gen Pract 1974;24:251-61.

attendance in a family practice. $\mathcal{F}$ R Coll Gen Pract 1974;24:251-61.
Stockwell F. The unpopular patient. London: Croom Helm, 1984.

6 Stockwell $F$. The unpopular patient. London: Croom Helm, 1984 .
7 Wamosher $Z$. The returning patient. A survey of patients with high attendance Wamosher $Z$. The returning patient. A survey of patients with high a
rates. Fournal of the College of General Practitioners 1966;11:166-73.

8 Semmence A. Chronic users in a general practice. A preliminary study. $7 \mathrm{R}$ Coll Gen Pract 1969;17:304-10.

9 Marinker $M$. Journey to the interior: the search for academic general practice. fR Coll Gen Pract 1987;37:385-7.

(Accepted 8 June 1988)
London N10

T J Gerrard, MRCGP, general practitioner principal

\section{London N6 4QA}

J D Riddell, MRCGP, general practitioner principal

Correspondence and requests for reprints to: Dr T J Gerrard, 1 Dukes Avenue, London N10 2PS

\title{
Difficult patients: black holes and secrets
}

\author{
T J Gerrard, J D Riddell
}

The despair, anger, and frustration that we feel with certain patients is part of our everyday lives; we are all familiar with that feeling which overwhelms us when we see Mr or Ms X's name in the visit book. We have been taught that these feelings often originate in the patient, and we try to use this insight to help them.

These patients usually attend frequently; it is not this that causes difficulty but the style and the content of the consultation. They often seek out a particular partner in the practice and then stay with him or her, and this special relationship can cause intense rivalry and resentment between partners. One doctor's list of difficult patients is not the same as another's, and this must reflect the needs and personalities of different doctors. We have found that a long case meeting to discuss these patients and the feelings they produce can be invaluable, but we also believe that further analysis of these particular patients as outlined in this paper can be helpful.

We looked at the first 25 names that came to mind and found that they all had one or more of $10 \mathrm{key}$ characteristics as described below. We have given examples based on real cases and suggested ways to understand and unlock patient and doctor. (Throughout the doctor is assumed to be male for the purposes of simplicity.)

\section{The ten categories}

BLACK HOLES

These patients demand help persistently but are expert at blocking it. There is no movement in their situation and they induce a feeling of helplessness in the carer. They are well versed in adopting an oppositional stance to whatever approach is made by the doctor. Younger inexperienced doctors feel especially vulnerable to their endlessly suffering, yet resisting, stance.

$\operatorname{Mrs} A$ is 79 years old and in her own words hasn't felt well for 25 years; her main complaints are exhaustion and weakness. She forms attachments, particularly to trainees in the practice, and is triumphant when their energy and interest do not reveal any underlying disease. Her four inch records show the extent of her success as a black hole.

The counter-The only approach likely to bring any relief is a paradoxical manoeuvre such as is used in family therapy_for example "There isn't a doctor in the world clever enough to help you" (response: "Well doctor, at least you tried"), or "I can't understand how you cope with what you have to and still want to go on living" (response: "I'll just go on trying a little bit longer").

\section{FAMILY COMPLEXITY}

It is impossible to disentangle these patients' problems from those of their family, and often the patient who presents is in reality the least sick member. They often have dysfunctional consultations as a result.

$M r$ and $M r s$ are both elderly and have spent a lifetime disliking each other. They compete for the 